\title{
Sharing our Stories: using an online encyclopaedia as the basis for a general education module on local history, creative writing and social justice
}

\author{
Graham Stewart' \\ Durban University of Technology \\ stewart@dut.ac.za
}

\begin{abstract}
Received: 10 October 2012
Accepted: 4 February 2013

Conventional wisdom suggests that the best way of equipping first-year university students with the skills to cope with the rigorous demands of discipline-specific discourse is through an "academic literacies" approach. In other words, by developing their abilities to discern different disciplinary contexts and settings, students may more confidently adopt appropriate linguistic practices in their studies (Archer 2010: 497). I would suggest that where the approach frequently falls short, is in the narrow range of discipline-specific materials provided for student consumption. To achieve the desired levels of linguistic agility for university study, students need a mental gymnasium with a truly challenging set of apparatus. It is not only students of literature who need exposure to creative writing. Reading of creative fiction can ignite the narrative imagination of the first-year university student, provoking an exploration of cultural diversity, social justice and identity. Novels, plays, poetry and short stories can engage the reader more deeply than factual studies, and engender a thoughtful, responsive and responsible attitude towards society. A sense of social justice is fundamental to the development of good citizenship, and it has been argued that the study of creative writing, especially that which is embedded in local and regional history, provides a sound scaffolding for student learning experiences through related writing activities and debate. Online literary and historical encyclopaedias can provide an ideal information landscape for the development of learning modules that focus on local literature. A structured e-learning module may build on such online sources by assisting the student to navigate the abundant references and discover materials that may be probed more deeply through reading assignments, writing tasks and discussion. This paper presents a case study of the design and development of a general education learning module - "Sharing our stories" - intended to provide students with enriching encounters with local literature while advancing their academic reading and writing skills. The module draws on the content of the Encyclopaedia of South African Arts, Culture and Heritage (ESAACH) which plays an integral part as a springboard to the exploration of local writing. While students encounter a variety of short stories, extracts from novels and biographical writing, a blog feature ensures that the students' own contributions are lodged within the bigger story what Ngugi wa Thiong'o calls the "collective history" - of our region (Wa Thiong'o 1986: xi).
\end{abstract}

Keywords: South African literature; virtual learning environment; online encyclopaedia; general education.

\section{Introduction}

Three interwoven strands constitute the e-learning module - a Virtual Learning Environment (VLE) called "Sharing our Stories" that is the subject of this discussion. The VLE is still in its design and development phase, with a proof-of-concept prototype being tested within a small community of practice drawn from lecturing and library staff at the Durban University of Technology. The three elements of the VLE are KwaZulu-Natal (KZN) Stories, extracts from the primary works of selected South African authors, students' own creative writing, and the online Encyclopaedia of South African Arts, Culture and Heritage (ESAACH), that acts as a scaffold for student learning, combining in one virtual space a reference source, pathfinder and digital library.

Informing each of the elements of the structure shown in Figure I are assumptions relating to the social function of literature, open access to information through an online encyclopaedia, the contribution of creative writing to the development of critical enquiry, and student-centred learning. For the purposes of this discussion the former two issues are considered at more length than the latter, although all the elements are touched upon within the totality of the VLE design. The influence of the VLE on student writing performance, critical thinking and attitude formation will be evaluated once the module has been piloted.

I. Associate Professor Graham Stewart is the Deputy Dean of the Faculty of Arts \& Design, Durban University of Technology, KwaZulu-Natal, South Africa. 


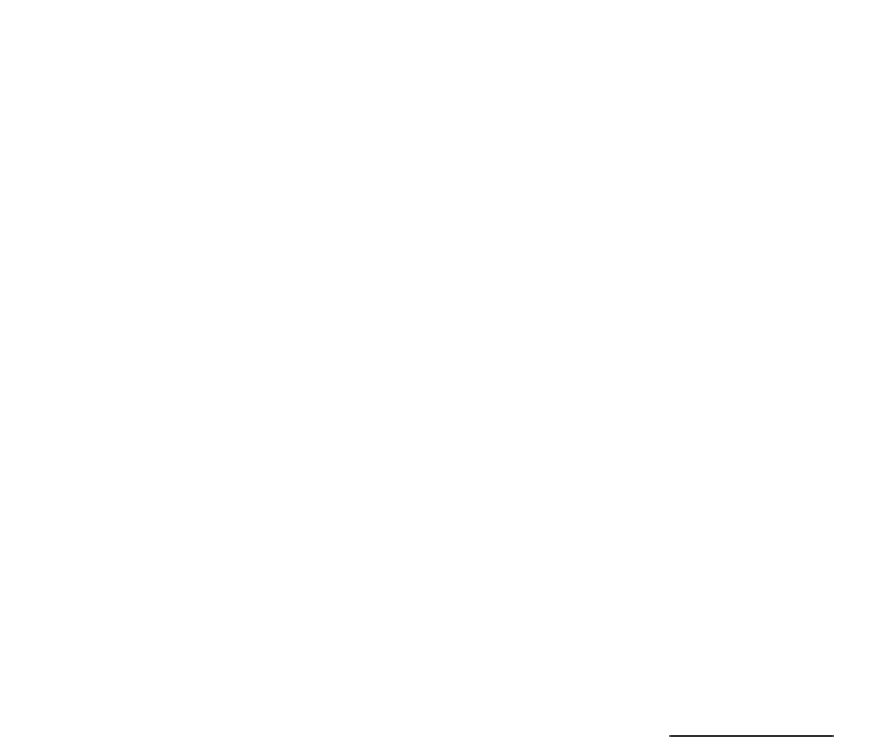

Figure 1 Constitutive elements of the VLE

The notion that the reading of works of literature may be of benefit to society is by no means taken for granted in the $2 I^{\text {st }}$ century. The inference that the reading great books will be good for you, make you a better citizen and a more wellrounded human being is a contested position, and perhaps quite understandably in an increasingly utilitarian and commodified world. "Few critics or scholars nowadays agree with the central tenets we ascribe to literary humanism, namely, that the pursuit of a literary culture will produce better people" (Jusdanis 20I0: I). Melvyn Bragg's celebrated 12 Books that changed the world (2007) contains only one literary work: Shakespeare's First Folio. Nevertheless, from Plato to present-day South Africa, the direct effect (either negative or positive) of reading is strongly held. Plato railed against the corrupting effects of $10^{\text {th }}$ century BCE Athenian arts and culture. In 2012, Priya Narismulu (2012: 136) argues that "Postcolonial fiction worthy of the name ... generate[s] further metacognitive development in all people yearning for greater freedom and justice". Both reflect a conviction in the profound effect emanating from the page, permeating the consciousness and influencing the subsequent attitudes and even the behaviour of the reader. There are echoes of Plato's qualms about the ill-effects of undeserving books in Narismulu's qualifier "worthy of the name" that only serves to emphasise the point. Many still believe that reading affects us. The selection of authors for the "Sharing our Stories" module deliberately subverts the old discredited literary canon of pre-democratic South Africa. Social conscience and the principle of "reclamation scholarship" (Mzamane and Stewart 2009) permeate the design and intention of the module. The thinking behind the choice of specific texts for inclusion in the module is addressed later in this discussion.

Contesting notions of the social function of literature in a South African context have been mapped out by Corinne Sandwith in an illuminating comparative study of two influential literary critics, Christina van Heyningen and Dora Taylor (1998). Both contributed to the debate on the role of literature in society during the 1940s and 50s, van Heyningen broadly arguing the case for the character-forming benefits for individuals of reading Great Works that would gradually develop the values of tolerance and social justice to produce a democratic citizenry: "“ ... To Shakespeare good and evil were not dead, nor can I think of any great writer who has not accepted the responsibility, explicitly or implicitly, of choosing between them, and who has not made the affirmation of values his chief right and function as an artist"' (van Heyningen, in Sandwith 1998: 17I). By contrast, Dora Taylor advanced the Marxist view that literature reflects great social and historical processes, and although not necessarily an agent of change in itself, is integral to the elimination of social injustice by providing critical social commentary. Taylor's view of the relationship between literature and society mirrors Trotsky's “ ' ... that the nightingale of poetry, like that bird of wisdom, the owl, is heard only after the sun has set. The day is the time for action, but at twilight feeling and reason come to take account of what has been accomplished."'(Trotsky 1925: 53 in Sandwith 1998: 183).

The visual arts are less diffident in asserting their potential influence on society. The Art and Social Justice International Conference, for instance, held in Durban in 2010, was predicated entirely on the assumption that such an influence could, and should, exist. UNESCO representative and speaker at the conference Damir Dijakovic indicated that UNESCO's 
patronage of the event was consistent with the aim of "promoting ethical values through artistic expression and creativity" (Dijakovic 2010: I). Similarly, there is no ambiguity in Kim Berman's assertion at the same conference that "The visual arts offer innovative methods for approaching social justice challenges and for achieving attitudinal and behaviour changes among individuals and communities" (Berman 2010: 65). The development of the "Sharing our Stories" project is testament to our conviction, embedded in the guiding principles of the General Education component of the Durban University of Technology Curriculum Renewal Project, that students should be exposed to literary works reflecting the voices and social history of their region (Timm et al. 2012). We hold the view that creative fiction (especially the work of local writers) should be incorporated into the curricula of South African universities of technology. Reflecting a sea-change in institutional attitudes towards the power of imaginative art, and literature in particular, in transforming the curriculum, is a view expressed by Ahmed Bawa, who goes beyond merely suggesting that literature may positively influence student development, to assert unequivocally that it would be "grossly irresponsible for educators not to expose our students to South African literature" (Vahed-Greer et al. 2012). Bawa goes on to call for a curriculum that can produce students "who can function effectively in a new democracy, who can function effectively in a burgeoning knowledge society, who have the skills to communicate, who have an understanding of South African literature and who have the capacity to make choices in terms of ethical frameworks" (Vahed-Greer et al. 20I2). It is no coincidence that one of the most celebrated advocates of clarity, precision and truth in the English language, George Orwell, was at root a writer of creative fiction. While his Politics and the English Language (1947) remains an influential guide to all writers, with its plea for plain-speaking and the avoidance of jargon, his depictions of the abuse of power through language in his novels Animal Farm (1945) and Nineteen Eighty-Four (1949), retain an even more chilling resonance today. Orwell himself models the mix of imagination, social conscience and mental acuity indispensable for an engaged citizenry. Avoiding imprecision and lazy writing habits leads to clear thinking, says Orwell, and "to think clearly is a necessary first step towards political regeneration ..." (Orwell 1947: 156).

\section{Is literature a social good?}

An important strand in the "Sharing our Stories" VLE is the online Encyclopaedia of South African Arts, Culture and Heritage $(E S A A C H)$ which was specifically developed as an open, non-canonical reference source designed to resist the language and ideological privileging of one text over another established within the colonial and apartheid social order. Although the wider aim of ESAACH is to promote reclamation scholarship, it also seeks to provide reference material for use in schools: "The project seeks, ultimately, to contribute to the process of decolonising the minds of all South Africans and reintegrating them to their collective and cumulative culture, history and heritage" (Mzamane and Stewart 2009). While the Encyclopaedia consists of a myriad of title and author entries, the VLE selection of authors proposes a new, temporary, canon: local KZN writing that voices a history of the city and the region, free of the orientalist lens that has for so long valorised Eurocentric writing and often left uncontested the values of colonial repression. The challenge for the "Sharing our Stories" developers is, in Sandwith's words, to select stories that " ... presuppose[ ] the ability of art to tell the 'truth' about history and society, and its ideological aims [ ] to restore personal dignity, and to act as a spur to political action" (Sandwith 1998: 185). The argument that critical thought and ethical grounding can be developed through the study of literature is reinforced by Martha Nussbaum: “ ... understanding the role from the point of view of the other is essential to any responsible act of judgment since we don't know what we're judging until we see the meaning of an action as that person intends it; the meaning of a speech as it expresses something of importance in the context of that person's history and social role" (1998: 44-45).

The "Sharing our Stories" module reflects general aims that underpin the South African national curriculum, including social justice, a healthy environment, human rights and inclusivity. Robinson (2010) in discussing the application of the national curriculum to the teaching of social justice through literature, touches on the unique quality of literature to provide concrete expression to otherwise abstract principles:

[...] in the field of literary study, it is not necessary to address social justice as a concept, directly, but rather to explore it through the medium of literary expression. The issues raised in the classroom devoted to literature might articulate effectively with debates derived from the concept of social justice, although the manner of engagement with the text would probably have to be directed by the teacher; it would seem to be unlikely that secondary school pupils would automatically engage with a literary text at this level without facilitation (Robinson 2010: 66).

We may reasonably assume that Robinson's inference that school pupils would not necessarily engage with a literary text with any degree of social insight, would apply equally to first-year university students at a university of technology who 
are the target audience for "Sharing our Stories". Careful selection of the extracts that make up the "KZN Stories" presented for student study is therefore crucial in assisting the lecturer or tutor to facilitate debate and discussion around the issues of social justice. Judicious selection may be the key to avoiding the dangers of a misleading canon, so central to the ideological debate between the liberal-pluralist position (represented by Christina van Heyningen in Sandwith's comparative study, discussed above ) and the contrasting view held by the Marxist Dora Taylor (Sandwith 1998). Fulela (20I2: II) brings the issue of the suitability of certain texts for student study into sharp focus by referring to "the problematic retention of literary works within syllabi that have been critiqued as complicit with the task of 'forming students into good liberal-humanists"'. Fulela here references Nick Visser's condemnation of the persistent choice of Conrad's novel Heart of Darkness by historically white South African universities as prescribed reading during the 1990s (Visser 1997: 90). Visser alludes to Chinua Achebe's celebrated attack on Conrad's novel as racist, and questions the value of keeping the book on reading lists. Achebe has remarked elsewhere, in reference to American students coming to African literature, that novels like Heart of Darkness promote a sense that "there are no real people in the Dark Continent, only forces operating; and people don't speak any language you can understand, they just grunt, too busy jumping up and down in frenzy. This is what is in the minds of these students as they come to African literature" (Achebe, in Wilkinson 1992: 56). In one of the extracts chosen for "Sharing our Stories", Lewis Nkosi's protagonist in Mating Birds mocks the racist attitude of his (white) history professor, who insultingly commends to his class the views of "A great historian [who] once said of our beloved continent [ ...] that before the white man came there was no African history to speak of in this darkest of the Dark Continents" (Nkosi 1987: 104). Nkosi is referring to the views of a succession of colonial historians, including Reginald Coupland in the 1920s who wrote that until the arrival of missionary-explorer David Livingstone "it might be said Africa proper had had no history" and Hugh Trevor-Roper who as late as 1963 made the extraordinary claim that "there is only the history of Europeans in Africa. The rest is darkness" (Davidson 1989: 44-46). It is against this backdrop that the selection of texts and authors for "Sharing our Stories" must be considered.

George Samiselo has argued for the inclusion of literature in a university general education course in a paper delivered at the English Academy of Southern Africa International Golden Jubilee Conference in Cape Town in 20I I. In "Achebe's 'syllabus' for teaching African Literature: A celebration of internationally shared values", Samiselo proposes a liberal arts foundation course that would highlight the importance of reading and writing at first-year level. Samiselo recommends an African Literature component in the curriculum that would be a "rewarding social, moral and political encounter" for students, quoting Chinua Achebe in support of the view that literature has transformative value - as indeed, does Albie Sachs who articulates a vision for South African arts and culture thus:

The objective is not to create a model culture into which everyone has to assimilate. [...] Each cultural tributary contributes towards and increases the majesty of the river of South African-ness (Sachs 1991: 191).

The authors selected for "Sharing our Stories" reflect the notion of an author as "vehicle or conduit of received communal ideas" (Moran 1996: 188). These particular KZN authors also de-centre themselves in relation to their responsibility for their books: for example Aziz Hassim ascribes a collective input into his novel Lotus People (Molver and Basckin: 2003) as does Phyllis Naidoo. Deena Padayachee's introduction to the second edition of What's love got to do with it? And other stories pays tribute through numerous acknowledgments to members of the communities out of which his stories have evolved. The celebrated Kenyan author Ngugi Wa Thiong'o provides a similar insight:

Over the years I have come to realise more and more that work, any work, even literary creative work, is not the result of an individual genius but the result of a collective effort. There are so many inputs in the actual formation of an image, an idea, a line of argument and even sometimes the formal arrangement. The very words we use are a product of a collective history (Wa Thiong'o 1986: x-xi).

The study of KZN Literature in the "Sharing our Stories" module would, I believe, develop a student's "narrative imagination", one of the key abilities identified in Nussbaum's article for the development of "good citizenship" (Nussbaum 1998: 44) or "aesthetic simulation" (Jusdanis 2010: II). Moran (1996: 187) quotes Adam Smith who attributes the value of literature to its "moral capacity to make the reader see things from another's point of view", a view echoed in Nussbaum's formulation of the concept of "narrative imagination": “ ... the ability to think what it might be like to be in the shoes of someone different from oneself; to be an intelligent reader of that person's story; and to understand the emotions and wishes and desires that someone so placed might have, including the many ways in which social circumstances shape emotions and wishes and desires" (Nussbaum 1998: 44). Gregory Jusdanis defends the role of 
literature "to highlight itself as a separate realm of human practice wherein we can imagine alternate possibilities of human relationships and political institutions" (2010: 5).

For Egyptian writer Nawal Al Saadawi, there is "no real distinction between fiction and non-fiction". She argues that a novel goes deeper than a collection of factual studies, by bringing everything together for the reader - "body, mind and spirit" (Al Saadawi 20II).

A rationale for the "Sharing our Stories" VLE might follow this path:

- Books allow imaginative exploration of other's reality (imaginative gymnasium).

- Imaginative empathy helps develop insight into, and tolerance of, others.

- Insight and tolerance of others is a desirable aspect of good citizenry.

- Good citizenship can emerge from reading imaginative fiction.

This implies, however, that such reading is of "good" books that are non-polemical, true to life, honest, not maliciously misleading or one-sided, etc. All of these "non-desirables" may be depicted in good fiction, but must be seen within the perspective of the author's fictional landscape - a dialogical environment in which the reader may explore the "alternate possibilities" referred to by Jusdanis (2010:5) above. The case for local fiction is that such stories open up insights into the diversity of local history, especially when current histories have been overlaid with the dominant narratives of colonial and neo-colonial power, and are deeply orientalist in their perspective. We trust that the voices of the chosen local authors will counter the stereotypes of the colonial society by helping students navigate between the tolerance, diversity and relativism of liberal humanism on the one hand, and the social activism of postcolonial ideology on the other. We may be able in Narismulu's words to "counter[...] the histories of systemic violence that persist despite their long-established bankruptcy" (2012: 135).

\section{Encyclopaedias as springboards to deeper learning}

While encyclopaedias have long been recognised as valuable tertiary reference sources in education, the ubiquity of online sources, and in particular, Wikipedia, has demanded a concerted new wave of critical attention to their role in scholarship and learning programmes. At the root of anxieties amongst teachers at schools and universities over the profligate use of Wikipedia by their students, is its uncritical use as the only source of information for research - its indiscriminate incorrect treatment as a primary source (Rosenzweig 2006, Roush 2005, McHenry 2004). An important part of information literacy training stresses the important, but limited role that encyclopaedias and surveys can play in the research process. At their best, encyclopaedia entries can open the door to a concise overview of the scope of any subject - for instance the authors featured in the VLE - briefly sketching the critical and theoretical landscape before presenting references to primary works, and publications that contain full-scale studies on the subject. The well-crafted encyclopaedia entry is a launch pad to further research, not an end in itself. While this view will come as no revelation to an experienced academic or librarian, there is a widening gulf between the considered and systematic conception of the role of the encyclopaedia, and the increasingly common practice amongst students of carelessly gleaning the most superficial summary from Wikipedia, and then venturing no further into the literature. One hears academics report that they have banned their students from citing Wikipedia. Eminent American historian Roy Rosenzweig disagrees. Writing in The Journal of American History Rosenzweig defends his focus on the role of Wikipedia thus: "one reason professional historians need to pay attention to Wikipedia is because our students do" (2006: 136). Rosenzweig goes on to advocate training students to be more discriminating in their use of online encyclopaedias, and, more radically, encourages academics to participate, both as contributors and moderators (editors) to Wikipedia itself. At the end of an extensive comparison of Wikipedia entries and those to be found in more acceptably authoritative texts like the American National Biography Online and Encyclopaedia Britannica - that academics would have no qualms in accepting in an assignment reference list - Rosenzweig concludes that by and large there are no major advantages in consulting the more conventional reference sources. In a similar vein, in a blind comparison test conducted by Nature magazine, the authors concluded that Britannica's advantage was not great in respect of scientific articles (Giles et al. 2005: 90 I), and scientist Edward Felten found that four out of six entries in Wikipedia were better than the similar articles to be found in Encyclopaedia Britannica (Felten 2005).

The intention to use the content of an encyclopaedia of Southern African literature as resource for e-learning is to be found in the development of the South African Literary (SALIT) Database in the mid-1990s. The germ of the idea of a South African literature virtual classroom is rooted in a joint project of Prof Johan van Wyk and the present author, called the "SALIT Backpack". The Backpack was conceived as a virtual learning environment (VLE) aligned with the encyclopaedia and designed to challenge the received master narrative of colonial history perpetuated by apartheid education, by 
guiding students through a new history of Southern African literature, starting with materials relating to hunter-gatherer rock art and lore, and Harkhuf's 2300 BCE account of his "Four Journeys to the Unknown South". It was an enterprise intended to reclaim African history.

The project not only challenged the entrenched narratives of colonial history but also the conventional media of dissemination. SALIT coincided with the momentous appearance of the World Wide Web and embraced the new medium's promise of wider access to all: "[...] the conventional divisions between bibliograp[ies], books themselves and learning environments are dissolving [ ...] during the course of the development of the SALIT Web, the electronic medium has transformed our original intentions by crossing the boundaries of reference work, library and classroom (Stewart and Van Wyk 2000: 7). Similarly, the "Sharing our Stories" VLE seeks to combine the valuable attributes of an encyclopaedia, a library pathfinder and a digital library. Whereas in the past, the conventional library pathfinder was limited to a particular library collection, the VLE can reference a variety of sources across the Internet, and include annotations or synopses that amount to the equivalent of a typical encyclopaedia entry: for an author, this would include birth and death dates, a brief biographical account and a synopsis of the writer's works, including links to other sources.

\section{The VLE as online repository, platform for student engagement, and guided learning path}

The various manifestations of VLE originating from ESAACH share the characteristic virtual classroom model in which access is limited to a prescribed group of learners and instructors/facilitators. This model, typified by Learning Management Systems (LMSs) like WebCT/Blackboard and Moodle, create a private online community within which students may share ideas, build their own materials and submit assignments. While the VLE usually provides hyperlinks to materials and sources on the World Wide Web, learning materials developed specifically for the course are kept within the virtual classroom itself and are accessible only to registered participants in the learning programme. Extracts from the work of KZN authors, for example, are available only within the classroom, and permission to use electronic reproduction was sought via the Durban University of Technology's IP office and, where possible, from the authors themselves.

Libraries have tended to encourage reading within the context of outcomes-based education (OBE) and the critical crossfield outcome of Information Literacy. The intention of "Sharing our Stories" is to encourage reading for the love of it, not primarily as information retrieval. There are dangers in adopting a technicist approach to the development of academic literacy, as it may be at least one contributory factor to the decline in reading as a popular activity amongst students, and the general degradation of the importance placed on imaginative fiction in our universities. "The literary qualities of reading expect the inculcation of such values as taste, discrimination and evaluation. OBE reading encourages tracking down information on a subject but says little about sifting quality from rubbish" (Dick 200I: 43). The same author criticises the LIS community for ignoring this important aspect of information literacy and accuses them of neglecting their social or public intellectual obligations (Dick 200I: 42). Recently, academic libraries have introduced interventions to redress this situation by actively promoting a culture of reading. For instance, the establishment of book club initiatives at universities, has led to the release of funds for the purchase of new fiction, and facilitated studentoriented book launches, poetry readings and discussion groups. A module on local writers provides an excellent opportunity for librarians and lecturers to join forces in encouraging a culture of reading.

\section{Sharing our Stories - online classroom}

A brief snapshot of part of the Learning Path may provide a sense of how a student might navigate the VLE:

1. Read Phyllis Naidoo's account of Gladys Manzi.

Go to discussions and give a short answer to this question: Why do you think Gladys Manzi was reluctant to tell her story to the young men (p. 95)? Read the comments made by other students in your group and make at least one response, giving your reaction to their opinions.

Instructor guidelines: Point to citizenship/social justice issues, what features of this story make you want to read more? Do you find it valuable to know more about local history?

Each link below opens an extract from the work of these extraordinary KZN writers:

Phyllis Naidoo

Mandla Langa

Deena Padayachee

Aziz Hassim

Lauretta Ngcobo

SA Jnl Libs \& Info Sci 20I2, 78(2) 


\section{Lewis Nkosi}

Harold Strachan

\section{Family Tree/ izithakazelo}

Follow the instructions to build a family tree on the MyHeritage site.

Post the URL of your family tree on the blog.

Go to discussions and comment on at least one of your group member's family tree.

\section{KZN Stories}

Answer quiz questions relating to characters and background of the story.

Write a review, persuading a friend or relative to read the story (similar to the reader comments on Amazon.com).

Use additional information from the ESAACH and KZN Literary Tourism sites.

Post your review on the blog.

Find the book in the library and read it!

Select one author, and find new information from newspapers, websites, or personal contact. Describe the information (interview, newspaper review or feature article, etc.) scan the information and upload to the blog. Consult this publication - Rosenberg, L. 2007. Wellspring of Hope: The Legacy of a Sports Field. Durban: Durban University of Technology Publication. Email a friend describing the project and its relation to the university. Locate any of the authors who are still around, to request an interview to discuss their books. Record the interview and upload it to the blog (refer to the interviews with Lewis Nkosi, Harold Strachan and Aziz Hassim as a guide to the type of questions to ask).

\section{The future}

A promising further development for the VLE is the creation of an online database or repository of local stories and local history generated by the student participants in the "Sharing our Stories" module. Students are expected to create their own family trees or izithakazelo as part of the learning path, and then to use these as the basis of their own stories or memoirs to be published in their personal blogs within the VLE. An excellent established model for such a venture is the Ulwazi project (Greyling and McNulty 2012) which has been successful in mobilising local communities to generate online indigenous knowledge databases, with libraries playing the "anchor role as custodian of the knowledge resource". By using a similar model to curate and store the stories of the student participants in the VLE, we may more effectively create a learning environment which is centred around the student's own contribution to a collective history, in a learnercentred environment in which "students are responsible for determining what is important in the problem they are solving [ ... These are environments in which instruction is more than a transaction of information from the machine to the student" (Orrill 2002: 2).

\section{References}

Al Saadawi, N. 20II. Talking Books. BBC World TV Interview. 27 November 201 I.

Archer, A. 2010. Challenges and potentials for Writing Centres in South African tertiary institutions. South African Journal of Higher Education, 24(4): 495-510.

Berman, K. 2010. Art and social justice: Exploring the link between art, social justice and health. In T. Starkey and J. Jordaan (eds) Proceedings of the 'Art and Social Justice' International Conference. Durban University of Technology, 2I-24 March 2010, 65-78.

Bragg M. 2007. Twelve books that changed the world. London: Hodder and Stoughton.

Davidson, B. 1989. The Ancient World and Africa: Whose Roots? In Ivan Van Sertima (ed), Egypt Revisited, Journal of African Civilizations, 10: 39-52.

Dick, A.L. 200I. Reading and Outcomes-Based Education: Should Income be the Key Outcome? Perspectives in Education, I9(2): 37-48.

Dijakovic, D. 2010. Introductory conference address. In T. Starkey and J. Jordaan (eds) Proceedings of the 'Art and Social Justice' International Conference. Durban University of Technology, 2 I-24 March 20 I0, I-5.

Felten, E. W. 2005. Wikipedia quality check. Retrieved Freedom to Tinker (blog). [Online] Available: http://www.freedom-totinker [site accessed I 4 January $20 \mathrm{II}$.

Fulela, B. 2012. Of Hauntings, Impasses and Lacunae: The South African Debate on Postcolonial Theory. Journal of Literary Studies, 28(3): 1-16.

Giles, J. et al. 2005. Internet Encyclopaedias Go Head to Head. Nature, 438: 900-90I, Dec. I5, 2005. [Online]. Available: http:/ /www.nature.com/nature/journal/v438/n7070/full/438900a.html [site accessed I 2 January $20 \mathrm{II}$ ].

Greyling, B. and McNulty, N. 2012. How to build an Indigenous Digital Library through Community Participation: the case of the Ulwazi Programme. Information for Sustainable Development in a Digital Environment. XXth Standing Conference of Eastern, Central and South Africa Library and Information Associations (SCECSAL) 20I2. Nairobi, Kenya. 4-8 June 2012.

Hassim, A. 2002. The Lotus People. Durban: STE Publishers. 
Jusdanis, G. 2010. Fiction Agonistes: In Defense of Literature. Stanford: Stanford University Press.

Langa, M. 2000. The Memory of Stones. Cape Town: David Philip.

McHenry, R. 2004. The Faith-Based Encyclopedia. Technology, Commerce and Society Daily, I5 November. [Online] Available: http://www.ideasinactiontv.com/tcs_daily/2004/II/the-faith-based-encyclopedia.html [site accessed 8 April 20 I I].

Molver, Z and Basckin, D. 2002. Harold Strachan. Guerilla, Painter, Writer. Video. Durban: KZN Literary Tourism. [Online]. Available:

http://www.literarytourism.co.za/index.php?option =com content\&view

$=$ article\&id $=42 I$ :harold-strachan\&catid=22\&ltemid $=\overline{49}$ [site accessed I5 August 20I2].

Molver, Z and Basckin, D. 2003. Aziz Hassim - An Interview. Video. Durban: KZN Literary Tourism. [Online]. Available: http://www.literarytourism.co.za/index.php?option =com_content\&view =article\&id=422:azi z-hassim\&catid=22\&/temid =49 [site accessed I5 August 20I2].

Moran, S. 1996. The New Hellenism. In Smit, J.A., J. van Wyk, and J-P. Wade (eds). Rethinking South African Literary History. Durban: Y Press: I77-195.

Mzamane, M. V. and Stewart, G.D.J. 2009. About ESAACH - ESAACH Website. [Online] Available: http://www.esaach.org.za/ index.php?title =ESAACH:About [site accessed 24 February 20I2].

Naidoo, P. 2002. Footprints in Grey Street. Durban: Far Ocean Jetty.

Narismulu, P. 2012. Teaching Social Justice and Diversity through South African Stories that Challenge the Chauvinistic Fictions of Apartheid, Patriarchy, Class, Nationalism, Ethnocentrism. Alternation, I8(I): I35-I58.

Ngcobo, L. 1981. Cross of Gold. Cape Town: Longman.

Nkosi, L. 1987. Mating Birds. Johannesburg: Ravan Press.

Nussbaum, M.C. 1998. Cultivating humanity: a classical defense of reform in liberal education. Liberal Education, 84(2): 38-45.

Orrill, C.H. 2002. Learning objects to support inquiry-based, online learning. In D.A. Wiley (ed), Instructional use of learning objects. Bloomington: Association for Educational Communications and Technology. [Online] Available : http://reusability.org/ read/ [site accessed 24 February 20I2].

Orwell, G. [1947] 1970. Politics and the English Language. In S. Orwell, S and I. Angus (eds) The Collected Essays, Journalism and Letters of George Orwell, Volume 4: In Front of Your Nose 1945-1950. Harmondsworth: Penguin Books.

Padayachee, D. 2003. What's love got to do with it? And other stories. Durban: USM Publishing.

Robinson, D. 2010. Alan Paton's Literature and the Teaching of Social Justice. English Academy Review, 27 (2): 60-70.

Rosenberg, L. 2007. Wellspring of Hope: The Legacy of a Sports Field. Durban: Durban University of Technology Publication.

Rosenzweig, R. 2006. Can History Be Open Source? Wikipedia and the Future of the Past. The Journal of American History, 93(I): II7-146.

Roush, W. 2005. Larry Sanger's Knowledge Free-for-All. Technology Review, I08(I): 2 I.

Sachs, A. 199I. Preparing ourselves for freedom: culture and the ANC constitutional guidelines. The Drama Review, 35 (I): I87193.

Samiselo, George. 20II. Achebe's “syllabus” for teaching African Literature: A celebration of internationally shared values. Paper presented at the Literature, Literacy and Language Conference. English Academy of Southern Africa International Golden Jubilee Conference. Cape Peninsula University of Technology, Cape Town, 7-9 September 201 I.

Sandwith, C. 1998. A Social Function for Literature? Two Women Critics and South African English Literary Studies, 1939 1948. Alternation, 5(I): 169-190.

Stewart, G.D.J. and Van Wyk, A. J. 2000. The SALit CD-ROM: A virtual library of South African literature. Unpublished paper presented at CITTE 2000, Conference on Information Technology in Tertiary Education. University of Port Elizabeth, 28 June 2000.

Strachan, H. 2004. Make a Skyf, Man! Johannesburg: Jacana.

Timm, D. et al. 2012. General Education Guiding Principles. Gen Ed @ DUT (Blog). [Online] Available: http:// geneddut.wordpress.com/guiding-principles/ [site accessed II November 2012].

Vahed-Greer, H., Swift, O., Seedat, T. and Matyila, A. (eds). 2012. Curriculum Renewal Project: General Education is not just a FAD (Video). Durban University of Technology.

Visser, N. 1997. Postcoloniality of a special type: theory and its appropriations in South Africa. The Yearbook of English studies, 27: 79-94.

Wa Thiong'o, N. 1986. Decolonising the Mind. The Politics of Language in African Literature. London: James Currey/Heinemann.

Wilkinson, J, (ed). 1992. Chapter 4: Chinua Achebe. Talking with African writers: interviews with African poets, playwrights and novelists. London: James Currey, 46-57. 